УДК 316.4

$10.17213 / 2075-2067-2021-3-52-60$

\title{
ИНСТИТУЦИОНАЛИЗАЦИЯ \\ ЦИФРОВОГО ОБРАЗОВАНИЯ ВЫСШЕЙ ШКОЛЫ: \\ СОЦИОЛОГИЧЕСКИЙ АНАЛИЗ ПРОБЛЕМЫ СОЦИАЛИЗАЦИИ МОЛОДЕЖИ
}

\author{
(C) 2021 г. А. В. Рачипа , А. Т. Латышева**, С. И. Самыгин ${ }^{* * *}$
}

"Южнный федеральный университет, г. Ростов-на-Дону, Россия, Московский авиационный институт

(национальный исследовательский университет), г. Москва, Россия

${ }^{* *}$ Таганрогский институт имени А. П. Чехова (филиал), Ростовский государственный экономический университет (РИНХ), г. Таганрог, Россия ${ }^{* * *}$ Ростовский государственный экономический университет (РИНХ), 2. Ростов-на-Дону, Россия

Целью исследования является сочииологический анализ проблемы сочиализации молодежи в рамках институциионализаџии циифрового образования в высшей школе.

Методологическую базу исследования составляет институциональный подход П. Бергера и Т. Лукмана, в соответствии с которым образование рассматривается как важный институт, связанный с регулячуией процесса вторичной социализации молодежи.

Результаты исследования. Институционализация циифрового образования высшей школь является тем процессом, который показывает, что происходит переход к обществу нового типа - иифровому. Безусловно, как и любой общественный процесс, институичионализация циифрового образования обладает рядом проблем, которые связаны с проиессом социализации молодежи. Институциионализациия цฺифрового образования высшей школь изменяет и определяет контекст сочииализации современной молодежи, формирует ее соичальный характер и диктует нормы, правила и образиь поведения.

Перспективу исследования составляет дальнейший анализ трансформаций, которые будут происходить в институте высшего образования: дифференциация преимуществ и недостатков, угроз включения циифровых технологий в образовательный процесс.

Ключевые слова: институт высшего образования; высшая школа; иифровое образование; молодежь; институционализация; социализация.

\section{INSTITUTIONALIZATION OF DIGITAL EDUCATION IN HIGHER EDUCATION: A SOCIOLOGICAL ANALYSIS OF THE PROBLEMS OF SOCIALIZATION OF YOUTH}

\section{(C) 2021 A. V. Rachipa*, A. T. Latysheva**, S. I. Samygin ${ }^{* * *}$}

"Southern Federal University, Rostov-on-Don, Russia, Moscow Aviation Institute (National Research University), Moscow, Russia

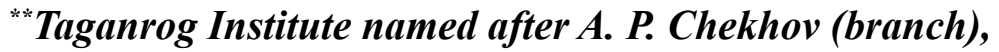
Rostov State University of Economics (RSUE), Taganrog, Russia

${ }^{* * *}$ Rostov State University of Economics (RSUE), Rostov-on-Don, Russia 
The purpose of the study is to sociological analysis of the problem of socialization of youth in the framework of the institutionalization of digital education in higher education.

The methodological base of the study is the institutional approach of P. Berger and T. Luckmann, according to which education is viewed as an important institution associated with the regulation of the process of secondary socialization of young people.

The results of the study. The institutionalization of digital higher education is the process that shows that there is a transition to a new type of society - digital. Of course, like any social process, the institutionalization of digital education has a number of problems that are associated with the process of socialization of young people. The institutionalization of digital higher education changes and defines the context of socialization of modern youth, forms its social character and dictates norms, rules and patterns of behavior.

The prospect of the study it makes a further analysis of the transformations that will take place in the institute of higher education: differentiation of advantages and disadvantages, threats to the inclusion of digital technologies in the educational process.

Key words: institute of higher education; high school; digital education; youth; institutionalization; socialization.

Введение. Современный этап институционализации цифрового образования в образовательном пространстве высшей школы «заключается в погружении всех его субъектов в цифровую образовательную среду» [1, с. 353]. Условия общественной жизни и уровень развития компьютерных технологий, а также быстрое развитие современного общества требуют пересмотра существующих взглядов на форму и содержание образовательного процесса в вузе $[2,3]$. Обращаясь к документу «О национальных целях и стратегических задачах развития Российской Федерации на период до 2024 года», мы видим, что Россия придерживается стратегии, направленной на научное и экономическое развитие государства [4]. В связи с этим система образования в Российской Федерации в настоящее время находится на этапе технологического и технического обновления, что приводит к появлению новых знаний и использованию новых технологий в образовательном процессе, направленных на институционализацию цифрового образования.

В России в настоящее время реализуется программа «Развитие образования» [5], в рамках которой действует проект «Современная цифровая образовательная среда в Российской Федерации» [6]. Данный проект направлен на то, чтобы активно внедрять цифровые технологии в российское образовательное пространство, а также институционализацию цифрового образования. Последняя необходима для эффективной организации и контроля учебной работы обучающегося учебного заведения со стороны как преподавателя, так и самого студента.

Высшее образование как общественный институт социализации. Прежде чем рассматривать проблемы трансформации высшей школы под влиянием фактора цифровизации, важно остановиться на рассмотрении института высшего образования как важного общественного института, связанного с процессом социализации молодежи.

В интерпретации общественного института мы прибегаем к подходу П. Бергера и Т. Лукмана, согласно мнению которых институты размещают человека, его существование и функционирование в контекст порядка, стабильности и управления [7]. Институционализация направлена на типизацию образцов действий у акторов различных процессов.

В рамках любого социального института каждый субъект обладает определенными ролями с набором конкретных действий. Институт образования не является исключением, так как акторы образовательного процесса играют в этом процессе свои роли, регулируемые системой существующих норм и правил. П. Бергер и Т. Лукман указывают на то, что каждая норма и правило диктуют определенные роли. Нормы и правила всегда зави- 
сят от ситуации. Ситуация меняется, нормы трансформируются [7].

Институт образования, в том числе и высшая школа, активным образом участвует в процессе вторичной социализации личности. В настоящее время управление образованием происходит «формальными организациями, которые не имеют другой цели, кроме образования» [8, с. 195]. В системе высшего образования молодой человек утрачивает свой уникальный статус, полученный в рамках первичной социализации в семье. «Здесь он наряду с другими выполняет либо роль обучающегося, либо роль преподавателя, либо роль администратора» [9, с. 86-87].

Основной функцией социального института образования является социальный контроль личности.

Обращаясь к идеям В.Н. Мининой, отметим, что проведение институционального анализа включает в себя рассмотрение той ситуации, которая наблюдается в системе высшей школы, тех норм и ценностей, которые существуют при цифровой трансформации высшей школы [9].

Институционализация цифрового образования в образовательном пространстве высшей школы, по мнению российских исследователей (Е.А. Карапетян, В. М. Ефимовой, Н.В. Якса и др.), способствует формированию нового вида социализации молодежи - т.н. киберсоциализации [10]. Иными словами, формируется новое, цифровое пространство социализации молодежи, которое определяется цифровыми средствами коммуникации и погружением образовательного процесса в технологическую среду.

Цифровизация высшего образования. Цифровизация образования - это цифровая трансформация образовательного процесса, включающая в себя создание и постоянное обновление цифровой инфраструктуры образовательного процесса, формирование базы цифровых учебно-методических материалов, использование в процессе обучения цифровых сервисов, ведение электронных журналов и организацию учебного процесса с применением интерактивных форм работы.

Суть цифровизации образования заключается в том, что при помощи использования цифровых технологий будут достигнуты вы- сокие показатели в образовательном процессе. То есть образование проходит этап цифровой трансформации, в котором цифровые инструменты делают образовательный процесс более эффективным, но усиливают профессиональную нагрузку на профессорскопреподавательский состав и требуют новых компетенций для владения новыми цифровыми инструментами.

Цифровизация института образования продиктована внешними факторами, которые в свою очередь обосновывают появление новых федеральных образовательных стандартов или собственных образовательных стандартов, разработанных вузом самостоятельно, готовность преподавателей использовать цифровые инструменты при реализации учебных курсов, способность распознавать и осваивать новое, распространять результативные организационные формы и методы учебной работы. То есть без активного участия педагогического сообщества в цифровой трансформации цифровизация института образования не может состояться.

\section{Институционализация онлайн-образо-} вания в высшей школе. Повсеместное и тотальное внедрение цифровых технологий, коснувшееся и высшей школы (т.н. цифровизация), привело к процессу институционализации онлайн-образования, повлекшей за собой определенные последствия и проблемы.

Фокус научно-исследовательского интереса в последние годы обращен именно к проблематике институционализации цифрового образования высшей школы и возникшим в свете данного процесса трансформационным проблемам. Так, Н.П. Петрова и Г.А. Бондарева проводят анализ этапов институционализации цифрового образования в высшей школе и рассматривают цифровые технологии, активно внедряющиеся в образовательные процессы и приводящие к цифровой трансформации образования [1]. В частности, авторы отмечают, что стратегия цифровизации образования предполагает внедрение таких инновационных технологий, как искусственный интеллект (технология, применяемая для решения интеллектуальных задач), блокчейн (технология, обеспечивающая хранение данных, например, информации об экзаменах, выданных дипломах и пр., об- 
ладающая распределенным ресурсом), виртуальная реальность (технология, в которой обучающийся взаимодействует или погружается в виртуальный мир посредством той или иной компьютерной программы) [1, с. 354].

Цифровая трансформация в высшем образовании влечет за собой изменение содержательной формы курса, что отражается на инструментах и технологиях преподнесения информации. Связано это с тем, что работа в дистанте отличается от работы оффлайн.

Если мы снова обратимся к Федеральным государственным образовательным стандартам по различным направлениям обучения, то увидим, что организация может использовать электронное обучение и различные образовательные технологии для опосредованной работы с обучающимися.

Эпидемиологическая ситуация в стране создала для всех российских вузов новую образовательную реальность [11]. В период пандемии, когда был введен режим самоизоляции, университеты были переведены на дистанционное обучение, что позволило преподавателям и студентам взаимодействовать при помощи удаленных образовательных технологий.

\section{Проблемы социализации молодежи} в условиях цифровизации образования. Наряду с пока малоизученными возможностями цифрового обучения можно обозначить ряд проблем и рисков социализации молодежи в условиях внедрения цифровизации в систему образования.

Во-первых, отметим тот факт, что в настоящее время не существует концепции цифрового обучения, которая бы могла использоваться преподавателями вузов в рамках реализации своих дисциплин. Также нельзя пока найти убедительных доказательств, которые указывали бы на то, что цифровое обучение эффективней традиционного обучения.

Во-вторых, отметим, что дефиниции «информация» и «знание» носят совершенно разный характер и не являются взаимозаменяемыми. Знание представляет собой субстрат, наделенный смыслами, которые обладают разным семантическим наполнением и содержанием для разных акторов. Информация же представляет собой семиотическую, знаковую систему.
В-третьих, нельзя забывать о том, что обучение всегда включает в себя коммуникацию преподавателя и студентов, то есть процесс взаимодействия сторон образовательного процесса включает в себя три элемента - коммуникативный, интерактивный и перцептивный. Также в процессе общения акторов очень важно вербальное (словесное) и невербальное взаимодействие [12]. Конечно, каждое слово обладает смыслом, объяснение которого можно найти в толковых словарях, но очень важно, в рамках какого контекста сказано то или иное слово. Часто смысл сказанного зависит от невербальных характеристик речевой деятельности. Аллан Пиз отмечает, что в слове отражается лишь $7 \%$ смысла сказанного, невербальная коммуникация может рассказать гораздо больше $55 \%$ [13].

Также стоит отметить и то, что понимание слов, которые произносит человек, может складываться из возрастного, гендерного, национального, научного и других факторов.

Перцептивный компонент общения очень важен для взаимодействия людей, для восприятия ими информации и в целом для процесса социализации. По мнению психологов, в первые семь секунд человек непроизвольно решает для себя, будет ли он обращаться к тому или иному человеку с какой-то просьбой или вопросом. Даже если человек может подсказать нам что-то важное, но он вызывает неприязнь, мы стараемся избегать его. Но следует отметить, что в процессе обучения обучающийся не может выбрать самостоятельно преподавателя.

Следовательно, цифровизация образования ставит вопросы, связанные с коммуникацией преподавателя и обучающихся, так как это влияет на результаты обучения и на процессы вторичной социализации в институциональном пространстве высшей школы [14].

Институционализация цифрового образования высшей школы изменяет и определяет контекст социализации современной молодежи, формирует ее социальный характер и диктует нормы, правила и образцы поведения в повседневной жизни; вырабатывает у молодежи «отношение к явлениям действительности и порождает целый ряд дисфункций процессов социализации и социального контроля» $[15$, с. 80$]$. 
Таким образом, проведенный нами анализ показывает, что информационные технологии не обладают способностью превращать значения в смыслы [12].

Уже описаны некоторые деструктивные эффекты воздействия цифровой образовательной среды на профессиональную социализацию молодежи, которые были определены при анализе данных, полученных в процессе данных экспертного интервью. Ответы, полученные специалистами в области цифровизации образования, позволили идентифицировать три блока эффектов отрицательного влияния институционализации цифровых технологий в образовательный процесс на социализацию молодежи [16].

К первому эффекту можно отнести эффект когнитивной редукции. Данный эффект связан с тем, что у молодого поколения еще не сложилось критическое мышление, чтобы осуществлять отбор достоверной информации и происходит только поверхностное восприятие информации, необходимой для процесса профессиональной социализации.

Второй блок деструктивных эффектов явление цифрового алармизма и игромании, a также податливость манипуляциям массового сознания, что никак не способствует традиционному становлению личности в процессе социализации, в котором формируются адекватные правила, нормы и ценности и правила взаимодействия.

Третий блок деструктивных эффектов цифровизации образования - это эффекты коммуникативной деструкции, которая заключается в том, что стираются границы, барьеры, навыки межличностной и деловой коммуникации, неразвитость эмоционального интеллекта.

Исходя из проведенного анализа, мы видим, что институционализация цифрового образования в высшей школе трансформирует традиционный процесс социализации, меняет роль преподавателя высшей школы, который воспринимается как провайдер контента и ресурсов, то есть преподаватель в рамках цифровизации процесса обучения выступает в качестве инженера по обучению [17].

Заключение. Резюмируя все сказанное выше по институционализации цифрового образования высшей школы, отметим, что цифровизация меняет структуру образовательной среды и трансформирует роли акторов образовательного процесса. Исходя из этого, можно заключить, что институт высшего образования трансформируется под воздействием цифровизации образовательного пространства высшей школы, a также приводит к трансформации процесса социализации молодежи. Формируется новое пространство социализации молодежи по мере институционализации цифрового образования, которое определяется технологической средой и цифровыми средствами коммуникации. В этой связи появляются проблемы вторичной социализации молодежи в условиях цифровизации образовательного пространства.

Однако при переходе на цифровые платформы в условиях институционализации цифрового образования высшей школы критически важным представляется сохранение традиционных аудиторно-контактных форм образования, составляющих фундамент процесса социализации.

\section{Литература}

1. Петрова Н.П., Бондарева Г.А. Цифровизация и цифровые технологии в образовании [Электронный ресурс] // МНКО. 2019. - №5 (78). - Режим доступа: https:// cyberleninka.ru/article/n/tsifrovizatsiya-itsifrovye-tehnologii-v-obrazovanii (Дата обращения: 13.02.2021).

2. Гафиатулина Н.Х., Рачипа А.В., Самысин С.И. Информационная сетевая среда как фактор влияния на социальное здоровье российской студенческой молодежи // Гуманитарные, социально-экономические и общественные науки. - 2018. - №1. - С.23-27.

3. Васьков М.А., Ковалев В.В., Гафиатулина H.X. Онлайн-образование в высшей школе России: основные акторы институционализации и социальные последствия // Гуманитарий Юга России. - 2020. — №2. C. 33-50.

4. Decree of the President of the Russian Federation of May 8, 2018 №204 «On national goals and strategic objectives of the development of the Russian Federation for the period up to 2024» [Electronic resource]. — URL: http:// 
kremlin.ru/events/president/news/57425 (Date accessed: 15.02.2021).

5. Decree of the Government of the Russian Federation of December 26, 2017 №1642 «On approval of the state program of the Russian Federation» Development of education (with changes and additions) [Electronic resource]. - URL: https://base.garant.ru/71848426/\#block_31.

6. Priority project in the field of education «Modern digital educational environment» [Electronic resource]. - URL: http://neorusedu.ru/.

7. Бергер П., Лукман Т. Социальное конструирование реальности. Трактат по социологии знания / пер. Е. Рудкевич. — М., 1995.

8. Бергер П.Л., Бергер Б., Коллинз Р. Личностно-ориентированная социология / пер. с англ. В. Ф. Анурина. — М., 2004.

9. Минина В.Н. Цифровизация высшего образования и ее социальные результаты [Электронный ресурс] // Вестник Санкт-Петербургского университета. Социология. 2020. - Т. 13. - Вып. 1. - С. 84-101. Режим доступа: https://doi.org/10.21638/ spbu12.2020.106.

10. Karapetyan E.A., Gafiatulina N. Kh., Efimova V.M., Yaksa N.V., Luginina A.G., Prokhorenko O.N. Cyber socialization as a factor of influence on the social health of student youth in a modern educational environment under the development of a global information society // Revista Gênero e Direito. — 2020. — Vol. 9. №4. - P. 830-845.

11. Гафиатулина Н.Х., Латышева А.Т., Самыгин С.И. Волонтерская деятельность в системе организации социальной работы с молодежью группы риска // Гуманитарные, социально-экономические и общественные науки. - 2020. - №1. - С. 27-30.

12. Вербицкий А. А. Цифровое обучение: проблемы, риски и перспективы [Электронный ресурс] / А. А. Вербицкий // Электронный научно-публицистический журнал «Homo Cyberus». - 2019. — №1 (6). - Peжим доступа: http://journal.homocyberus.ru/ Verbitskiy_AA_1_2019.

13. Пиз A. Язык телодвижений. - Нижний Новгород, 1992. - 272 с.

14. Gafiatulina N. Kh., Rachipa A.V., Vorobyev G.A., Kasyanov V.V., Chapurko T. M., Pavlenko I.I., Samygin S. I. Socio-political changes as a socio-cultural trauma for the social health of Russian youth // Modern Journal of Lan- guage Teaching Methods. - 2018. - Vol. 8. №5. - P. 602-609.

15. Кулишов В. В. Риски воспитания растущего человека в условиях информатизированной массовой культуры: ноогенный синдром как препятствие самоактуализации обучающихся / Всероссийская научно-практическая конференция «Трансформация смыслов образования в условиях цифровизации общества». - Краснодар, 2020. - С. 78-83.

16. Бородовская Е. В., Домбровская А. Ю., Пьима Р.В., Синяков А.В., Азаров А.А. Влияние цифровых коммуникаций на офрмирование профессиональной культуры российской молодежи: результаты комплексного прикладного исследования // Мониторинг общественного мнения: Экономические и социальные перемены. - 2019. — №1. C. 228-251.

17. Saykili A. Higher education in the digital age: The impact of digital connective technologies // Journal of Educational Technology \& Online Learning. — 2019. — №2 (1). — P. 1-15.

\section{References}

1. Petrova N.P., Bondareva G.A. Cifrovizacija i cifrovye tehnologii $\mathrm{v}$ obrazovanii [Digitalization and digital technologies in education] [Jelektronnyj resurs] // MNKO. - 2019. №5(78). - URL: https://cyberleninka.ru/ article/n/tsifrovizatsiya-i-tsifrovye-tehnologii-vobrazovanii (Date accessed: 13.02.2021).

2. Gafiatulina N.H., RachipaA.V., Samygin S.I. Informacionnaja setevaja sreda kak faktor vlijanija na social'noe zdorov'e rossijskoj studencheskoj molodezhi [Information network environment as a factor of influence on the social health of Russian student youth] // Gumanitarnye, social'no-jekonomicheskie i obshhestvennye nauki [Humanities, socio-economic and social Sciences]. - 2018. - №1. - Pp. 23-27.

3. Vas'kov M. A., Kovalev V.V., Gafiatulina N.H. Onlajn-obrazovanie v vysshej shkole Rossii: osnovnye aktory institucionalizacii $\mathrm{i}$ social'nye posledstvija [Online education in the higher school of Russia: the main actors of institutionalization and social consequences] // Gumanitarij Juga Rossii. — 2020. — №2. Pp. 33-50.

4. Decree of the President of the Russian Federation of May 8, 2018 №204 «On national 
goals and strategic objectives of the development of the Russian Federation for the period up to 2024» [Electronic resource]. — URL: http:// kremlin.ru/events/president/news/57425 (Date accessed: 15.02.2021).

5. Decree of the Government of the Russian Federation of December 26, 2017 №1642 «On approval of the state program of the Russian Federation» Development of education (with changes and additions) [Electronic resource]. - URL: https://base.garant.ru/71848426/\#block_31.

6. Priority project in the field of education «Modern digital educational environment» [Electronic resource]. — URL: http://neorusedu.ru/.

7. Berger P., Lukman T. Social'noe konstruirovanie real'nosti. Traktat po sociologii znanija [Social construction of reality. A treatise on the sociology of knowledge] / per. E. Rudkevich. Moscow, 1995.

8.Berger P.L., Berger B., Kollinz R. Lichnostno-orientirovannaja sociologija [Personalityoriented sociology] / per. s angl. V.F. Anurina. - Moscow, 2004.

9. Minina V.N. Cifrovizacija vysshego obrazovanija i ee social'nye rezul'taty [Digitalization of higher education and its social results] [Jelektronnyj resurs]// Vestnik Sankt-Peterburgskogo universiteta. Sociologija [Bulletin of the Saint Petersburg University. Sociology]. — 2020. Vol.13. - Issue 1. - Pp. 84-101. - URL: https://doi.org/10.21638/spbu12.2020.106.

10. Karapetyan E.A., Gafiatulina N. Kh., Efimova V.M., Yaksa N.V., $\quad$ Luginina A. G., Prokhorenko O.N. Cyber socialization as a factor of influence on the social health of student youth in a modern educational environment under the development of a global information society // Revista Gênero e Direito. — 2020. — Vol. 9. - №4. - P. 830-845.

11. Gafiatulina N. H., Latysheva A. T., Samygin S.I. Volonterskaja dejatel'nost' v sisteme organizacii social'noj raboty $\mathrm{s}$ molodezh'ju gruppy riska [Volunteer activity in the system of organizing social work with the youth of the risk group]// Gumanitarnye, social'no-jekonomicheskie i obshhestvennye nauki [Humanities, socio-economic and social sciences]. 2020. — №1. - Pp. 27-30.
12. Verbickij A.A. Cifrovoe obuchenie: problemy, riski i perspektivy [Digital education: problems, risks and prospects] [Jelektronnyj resurs] / A.A. Verbickij // Jelektronnyj nauchnopublicisticheskij zhurnal «Homo Cyberus». 2019. — №1 (6). - URL: http://journal.homocyberus.ru/Verbitskiy_AA_1_2019.

13. Piz A. Jazyk telodvizhenij [Body language]. - Nizhnij Novgorod, 1992. - 272 p.

14. Gafiatulina N. Kh., Rachipa A. V., Vorobyev G.A., Kasyanov V.V., Chapurko T.M., Pavlenko I.I., Samygin S.I. Socio-political changes as a socio-cultural trauma for the social health of Russian youth // Modern Journal of Language Teaching Methods. - 2018. — Vol. 8. №5. - P. 602-609.

15. Kulishov V.V. Riski vospitanija rastushhego cheloveka $\mathrm{v}$ uslovijah informatizirovannoj massovoj kul'tury: noogennyj sindrom kak prepjatstvie samoaktualizacii obuchajushhihsja [Risks of educating a growing person in the conditions of informatized mass culture: noogenic syndrome as an obstacle to self-actualization of students] / Vserossijskaja nauchno-prakticheskaja konferencija «Transformacija smyslov obrazovanija $\mathrm{v}$ uslovijah cifrovizacii obshhestva» [All-Russian scientific and practical conference «Transformation of the meanings of education in the conditions of digitalization of society»)]. Krasnodar, 2020. - Pp. 78-83.

16. Borodovskaja E. V., Dombrovskaja A. Ju., Pyrma R.V., SinjakovA.V., AzarovA.A. Vlijanie cifrovyh kommunikacij na ofrmirovanie professional'noj kul'tury rossijskoj molodezhi: rezul'taty kompleksnogo prikladnogo issledovanija [The influence of digital communications on the formation of professional culture of Russian youth: the results of a comprehensive applied study] // Monitoring obshhestvennogo mnenija: Jekonomicheskie i social'nye peremeny [Monitoring public opinion: Economic and social changes]. - 2019. - №1. - Pp. 228-251.

17. Saykili A. Higher education in the digital age: The impact of digital connective technologies // Journal of Educational Technology \& Online Learning. — 2019. — №2 (1). - P. 1-15. 


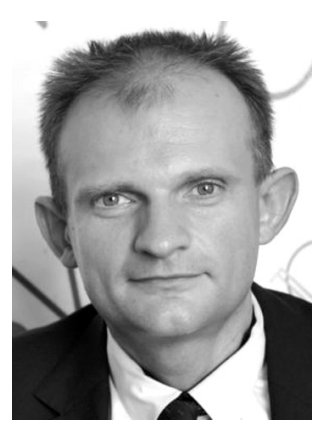

Рачипа Андрей Валерьевич - доктор социологических наук, профессор, заведующий кафедрой социологии, истории и политологии Института управления в экономических, экологических и социальных системах Южного федерального университета, профессор-совместитель кафедры 109Б Московского авиационного института (Национального исследовательского университета) в г. Москве.

Rachipa Andrey Valerievich - Doctor of Sociological Sciences, Professor, Head of the Department of Sociology, History and Political Science, Institute of Management in Economic, Environmental and Social Systems, Southern Federal University, part-time Professor of the Department 109B of the Moscow Aviation Institute (National Research University) in Moscow.

347900, г. Таганрог, ул. Энгельса, 1

1 Engelsa st., 347900, Taganrog, Russia

E-mail: rachipa@sfedu.ru

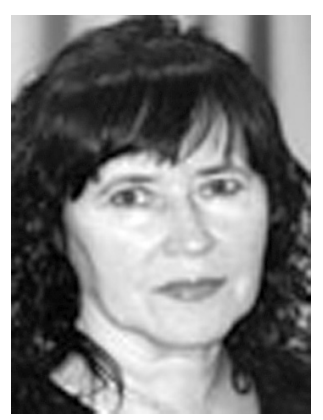

Латышева Анна Трофимовна - кандидат социологических наук, доцент кафедры педагогики и социокультурного развития личности Таганрогского института им. А.П. Чехова (филиала) Ростовского государственного экономического университета.

Latysheva Anna Trofimovna - Candidate of Sociological Sciences, Associate Professor of Pedagogics and Sociocultural Development of the identity of the Taganrog institute of A.P. Chekhov - branch of the Rostov State University of Economics (RSUE).

347900 , г. Таганрог, пер. Тургеневский, 32

32 Turgenevsky ln., 347900, Taganrog, Russia

E-mail: serg1952@mail.ru 


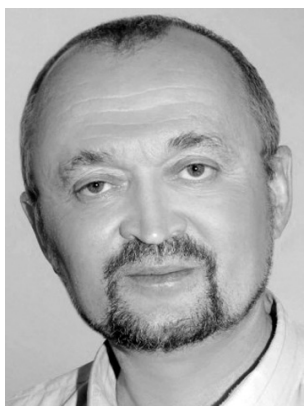

Самыгин Сергей Иванович - профессор, доктор социологических наук, профессор кафедры управления персоналом и социологии Ростовского государственного экономического университета (РИНХ).

Samygin Sergey Ivanovich - Professor, Doctor of Sociological Sciences, Professor, Department of Personnel Management and Sociology, Rostov State University of Economics (RSUE).

344002, г. Ростов-на-Дону, ул. Большая Садовая, 69 69 Bolshaya Sadovaya st., 344002, Rostov-on-Don, Russia E-mail: darya.maksimovich@gmail.com 